\title{
ANALISIS PENGERASAN PERMUKAAN DAN STRUKTUR MIKRO BAJA AISI 1045 MELALUI PROSES NITRIDASI MENGGUNAKAN MEDIA UREA
}

\author{
Umen Rumendi, Hana Hermawan \\ Dosen Teknik Material Jurusan Teknik Manufaktur, \\ Politeknik Manufaktur Negeri Bandung \\ Jl.Kanayakan no 21 Dago, code pos 40135 Bandung Indonesia \\ E-mail: umen rumendi2012@yahoo.com
}

\begin{abstract}
ABSTRAK
Nitridasi bertujuan untuk mengeraskan permukaan baja yang bertujuan untuk meningkatkan sifat kimia dan mekanik. Nitridasi yang dilakukan adalah nitridasi padat menggunakan urea sebagai alternatif sumber Nitrogen yang akan berdifusi dengan permukaan logam dan membentuk nitrida besiFe ${ }_{4} \mathrm{~N}$. Dalam penelitian ini, pengujian dilakukan terhadap tiga sampel baja dengan standar AISI 1045. Dalam penelitian ini yang menjadi variabel adalah suhu nitridasi, yaitu $460^{\circ} \mathrm{C}, 510^{\circ} \mathrm{C}$ dan $560^{\circ} \mathrm{C}$ dengan holding time dalam tungku, selama 4 jam. Hasil sampel yang telah dinitridasi selanjutnya dilakukan pengujian yang meliputi pengujian kekerasan permukaan, distribusi kekerasan dan observasi struktur mikro. Dari hasil pengujian yang dilakukan, maka didapatkan kekerasan tertinggi dari ketiga sampel adalah sampel 1 yang dilakukan nitridasi pada suhu $460^{\circ} \mathrm{C}$ dengan harga kekerasan permukaan rata-rata $440,5 \mathrm{HVN}$ kemudian posisi berikutnya berada pada sampel 2 yang dilakukan pada suhu $510^{\circ} \mathrm{C}$ dengan harga kekerasan permukaan $355,34 \mathrm{HVN}$, sedangkan sampel 3 yang dilakukan pada suhu $560^{\circ} \mathrm{C}$ dengan kekerasan permukaan 265,62. Dengan hasil ini pengerasan permukaan baja AISI 1045 dengan menggunakan media urea sebagai sumber nitrogen dapat meningkatkan kekerasan permukaan baja tersebut.
\end{abstract}

Keywords: Nitridasi, Nitrogen, Nitrida besiFe4N, Struktur mikro,AISI 1045

\section{PENDAHULUAN}

\section{Latar Belakang}

Teknik pengerasaan permukaan, merupakan suatu proses untuk meningkatkan sifat keras dari sebuah material terutama untuk baja. Peningkatan kekerasan pada permukaan baja bisa dilakukan dengan beberapa metode heat treatment, diantaranya adalah karburasi dan nitridasi. Tujuannya adalah untuk memberikan sifat keras dan tahan terhadap keausan. Kerusakan suatu permukaan baja biasanya dimulai dari kerusakan yang diakibatkan karena adanya interaksi dengan material lain atau dapat diakibatkan oleh pengaruh lingkungan, seperti korosi yang terjadi akibat adanya reaksi antara besi dengan oksigen yang membentuk oksidasi pada permukaan. Dalam dunia industri, teknik pengerasan permukaan sangatlah berguna untuk menghasilkan komponen yang tahan terhadap keausan akibat bergesekan antar komponen, serta tahan terhadap faktor lingkungan seperti korosi.
Beberapa teknik perlakuan permukaan yang biasa digunakan diantaranya nitridasi (nitriding), karburasi (carburizing), karbonitridasi (carbonitriding), pengerasan induksi dan pengerasan nyala api (flame hardening). Dari beberapa teknik perlakuan panas tersebut, teknik perlakuan panas yang akan digunakan dan dibahas dalam penelitian ini adalah teknik perlakuan panas dengan proses nitridasi (nitriding). Nitridasi merupakan suatu proses pengerasan permukaan dengan terlebih dahulu menambahkan unsur nitrogen pada permukaan suatu material baja, baik baja paduan maupun baja bukan paduan. Pada proses nitridasi secara konvensional dibedakan menjadi tiga cara, yaitu nitridasi gas (gas nitriding), nitridasi cairan (liquid nitriding) dan nitridasi padat (pack nitriding). Dalam proses nitridasi yang akan digunakan dalam penelitian ini adalah nitridasi padat yang dilakukan pada oven pemanas dengan menggunakan sumber nitrogen dari urea.

Nitridasi padat (pack nitriding) merupakan proses meningkatkan kekerasan permukaan baja 
dengan menggunakan nirogen dengan bantuan senyawa organik sebagai sumber nitrogen dalam prosesnya. Baja yang diproses dimasukkan kedalam wadah yang biasanya terbuat dari keramik, kaca atau aluminium bersamaan dengan senyawa yang digunakan sebagai sumber nitrogen. Selama pemanasan, senyawa organik yang digunakan dalam proses rata-rata bereaksi stabil pada suhu sampai dengan $570^{\circ} \mathrm{C}$ dan waktu penahanan 2 sampai dengan $16 \mathrm{jam}^{4}$. Dibandingkan dengan menggunakan nitridasi cair (liquid nitriding) yang waktu nitridasinya antara 4-72 jam dan rata-rata pemakaian 24 jam $^{5}$. Maka waktu yang digunakan dalam proses Nitridasi padat (pack nitriding) cenderung lebih cepat.

Baja karbon sedang (medium carbon steel) AISI 1045 adalah baja karbon yang mempunyai kandungan karbon sekitar 0,43 - 0,50 dan termasuk golongan baja karbon sedang. Baja dengan standar AISI 1045 ini banyak digunakan untuk komponen-komponen automotif misalnya untuk komponen roda gigi pada kendaraan bermotor, sproket, poros transportir dan sebagainya.

Tabel 1. Kandungan Unsure-Unsur Baja AISI 1045

\begin{tabular}{|lc|l|l|l|l|}
\hline ur & Uns & e & & i & n \\
\hline $\begin{array}{l}\text { entase } \\
(\%)\end{array}$ & $\begin{array}{c}\text { Pros } \\
(\%)\end{array}$ & 8,52 & $\begin{array}{l}, 43- \\
0,50\end{array}$ &, 3 &, 7 \\
\hline
\end{tabular}

Pada penelitian ini menggunakan sumber nitrogen dari pupuk urea. Pupuk urea dibuat secara kimiawi dengan kandungan kadar nitrogen yang cukup tinggi, mayoritas pupuk urea yang beredar di pasaran mengandung unsur hara nitrogen $(\mathrm{N})$ dengan kadar 46\%. Artinya setiap 100 kilogram pupuk urea, mengandung 46 kilogram nitrogen didalamnya. Pada umumnya pupuk urea memiliki tekstur yang cukup kasar. Pupuk urea berbentuk butiran-butiran seperti kristal berwarna putih dan memiliki rumus kimia $\mathrm{NH}_{2} \mathrm{CONH}_{2}$.

Dengan adanya kandungan nitrogen yang cukup tinggi pada pupuk urea, maka penelitian proses nitridasi pada permukaan baja ini, dilakukan dengan menggunakan urea sebagai sumber nitrogen. Pada temperatur 460-600 ${ }^{\circ} \mathrm{C}$ kandungan Nitrogen pada urea ini diharapkan terurai menjadi atom $\mathrm{N}$ yang nantinya akan berdifusi pada permukaan baja sampel uji, yaitu baja karbon sedang AISI 1045.

\section{TINJAUAN PUSTAKA}

\section{Nitridasi Gas}

Pada proses nitridasi ini menggunakan gas amonia (NH3), nitridasi dilakukan di dalam tanur (furnace) pada suhu antara $460^{\circ} \mathrm{C}-600^{\circ} \mathrm{C}$. Pada suhu ini amonia akan berdesosiasi sehingga menghasilkan atom hidrogen dan nitrogen dengan reaksi sebagai berikut:

$\mathrm{NH}_{3} \rightarrow 3 / 2 \mathrm{H}_{2}+\mathrm{N}$

Dari desosiasi ini selanjutnya atom nitrogen larut pada permukaan benda yang dinitridasi sehingga membentuk nitrida. Proses nitridasi pada umumnya diterapkan untuk pengerasan peralatan (komponen mesin) yang terbuat dari baja karbon medium dan baja paduan yang mengandung unsurunsur :Al, $\mathrm{Cr}, \mathrm{Mo}, \mathrm{Mn}$ dan unsur lain yang memungkinkan bereaksi dengan unsur nitrogen. Unsur-unsur baja tersebut akan bereaksi dengan nitrogen yang larut secara interstisi sehingga membentuk nitrida-nitrida seperti: $\mathrm{Fe}_{2} \mathrm{~N}, \mathrm{Fe}_{3} \mathrm{~N}$, $\mathrm{Fe}_{4} \mathrm{~N}, \mathrm{Cr}_{2} \mathrm{~N}, \mathrm{Mo}_{2} \mathrm{~N}$ maupun AlN.

\section{Nitridasi Cairan}

Pada proses nitridasi ini menggunakan cairan garam seperti cyanide-cyanite salts yang mengandung 60\% - 70\% NaCN (berat) dan 30\% - 40\% (berat). Proses ini diawali pencairan garam pada daerah suhu 560$570{ }^{\circ} \mathrm{C}$ dan waktu $1-2$ jam untuk membasahi permukaan baja yang dinitridasi. Kemudian dilanjutkan dengan proses nitridasi pada suhu $565-$ $595{ }^{\circ} \mathrm{C}$ dengan waktu sampai 12 jam. Untuk menghasilkan dengan reaksi sebagai berikut :

$4 \mathrm{NaCN}+2 \mathrm{O}_{2} \rightarrow 4 \mathrm{NaCNO}$

Sodium cyanate ini bersifat tidak stabil sehingga terurai menghasilkan nitrogen sebagai berikut :

$4 \mathrm{NaCNO} \rightarrow \mathrm{Na}_{2} \mathrm{CO}_{3}+2 \mathrm{NaCN}+\mathrm{CO}+2 \mathrm{~N}$

Selanjutnya atom nitrogen larut pada permukaan baja yang dinitridasi sehingga membentuk nitrida seperti pada nitridasi dengan gas NH3.

\section{Nitridasi Padat ${ }^{6}$}

Cara lain yang digunakan dalam proses nitridasi untuk pengerasan permukaan baja adalah dengan teknik nitridasi padat (pack nitriding). Nitridasi padat 
menggunakan nirogen dengan bantuan senyawa organik sebagai sumber nitrogen dalam prosesnya. Baja yang diproses dimasukkan kedalam wadah yang biasanya terbuat dari keramik, kaca atau aluminium bersamaan dengan senyawa yang digunakan sebagai sumber nitrogen. Selama pemanasan, senyawa organik yang digunakan dalam proses rata-rata bereaksi stabil pada suhu sampai dengan $570^{\circ} \mathrm{C}$. Reaksi dari senyawa tersebut terdekomposisi pada suhu nitridasi dan kemudian mengeluarkan sumber nitrogen. Waktu proses berkisar dari 2 sampai dengan 16 jam.

\section{METODE PENELITIAN}

Dalam penelitian ini proses persiapan sampel baja AISI 1045 menjadi dimensi 30x23x8 (mm) dengan banyak sampel empat buah. Persiapan berikutnya adalah menghaluskan permukaan sampel dengan mesin gerinda. Selanjutnya setelah itu dilakukan pengampelasan dengan tingkat kekasaran yang berbeda-beda, dimulai dari yang kasar hingga halus ( 120, 180, 220, 280, 320, 360, 400, 480, 600, 800, 1200 ) sampai mendapatkan permukaan sampel yang halus. Hal ini dilakukan untuk mempermudah proses pembacaan pada pengujian sampel menggunakan mesin uji kekerasan.

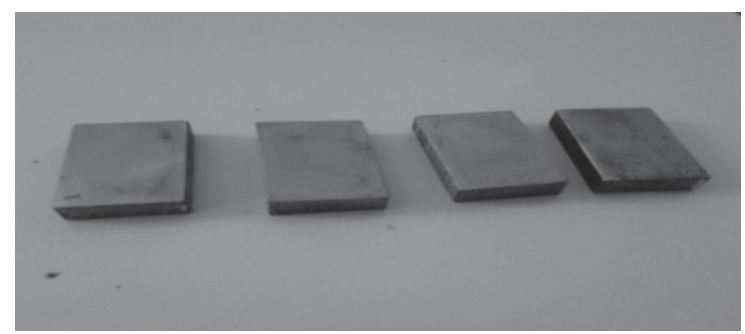

Gambar1. Sampel uji baja AISI1045 setelah dihaluskan pemukaannya

Persiapan berikutnya adalah membuat tabung reaktor nitridasi yang terbuat dari pipa baja dengan dimensi yang disesuaikan sebagai wadah penempatan urea dan sampel uji saat mengalami proses nitridasi di dalam tungku pemanas.

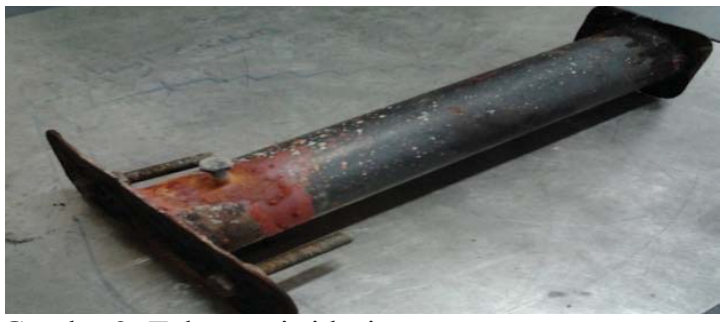

Gambar2. Tabung nitridasi

\section{Proses Nitridasi}

yang pertama, dilakukan proses nitridasi pada tiga sampel uji dengan variabel suhu yang berbeda, yaitu $460{ }^{\circ} \mathrm{C}, 510{ }^{\circ} \mathrm{C}$ dan $560{ }^{\circ} \mathrm{C}$ dengan lama waktu penahanan 4 jam. Proses nitridasi dilakukan dengan menggunakan tungku pemanas SS-1200 kapasitas $1200^{\circ} \mathrm{C}$.

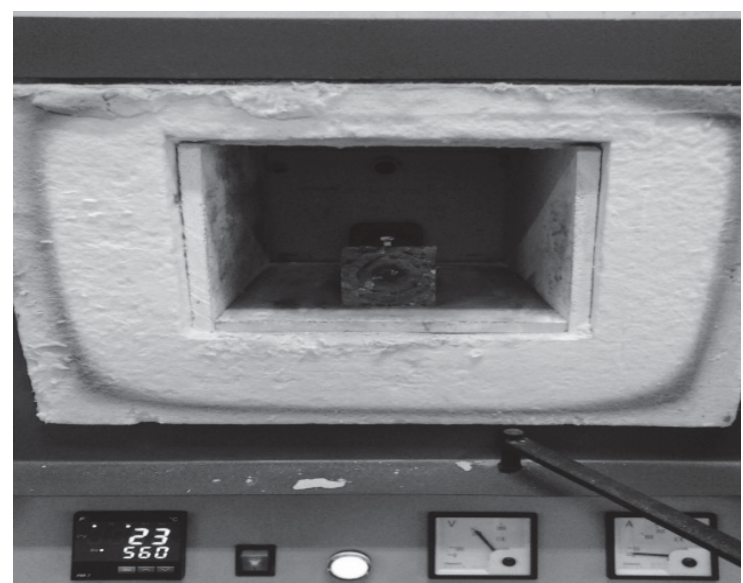

Gambar3. Proses Nitridasi dlam tungku pemanas

Proses pengujian, dilakukan observasi struktur mikro dan pengujian kekerasan vickers pada sampel uji yang masing-masing telah mengalami proses nitridasi dengan variabel suhu yang berbeda. Pengujian kekerasan permukaan dilakukan beberapa kali dengan jarak tiap titik pengujian $1 \mathrm{~mm}$ pada masingmasing sampel. Sedangkan pengujian depth of case dilakukan dengan cara memotong benda kerja melintang dan mengukur kekerasan dari sisi terluar dengan jarak masing-masing 0,05 mm. Kemudian hasil pengujian didata untuk diolah

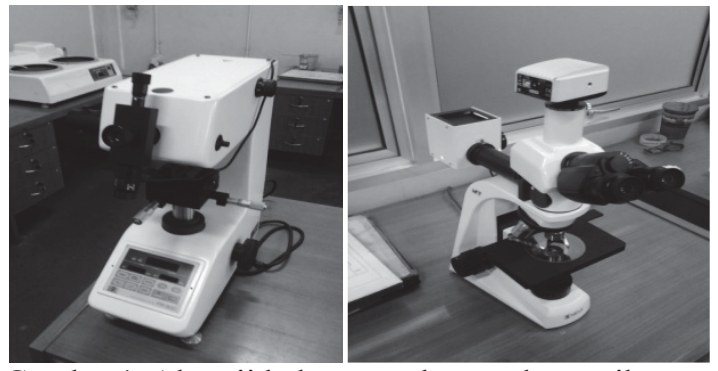

Gambar4. Alat uji kekerasan dan struktur mikro 


\section{Diagram Alir Penelitian}

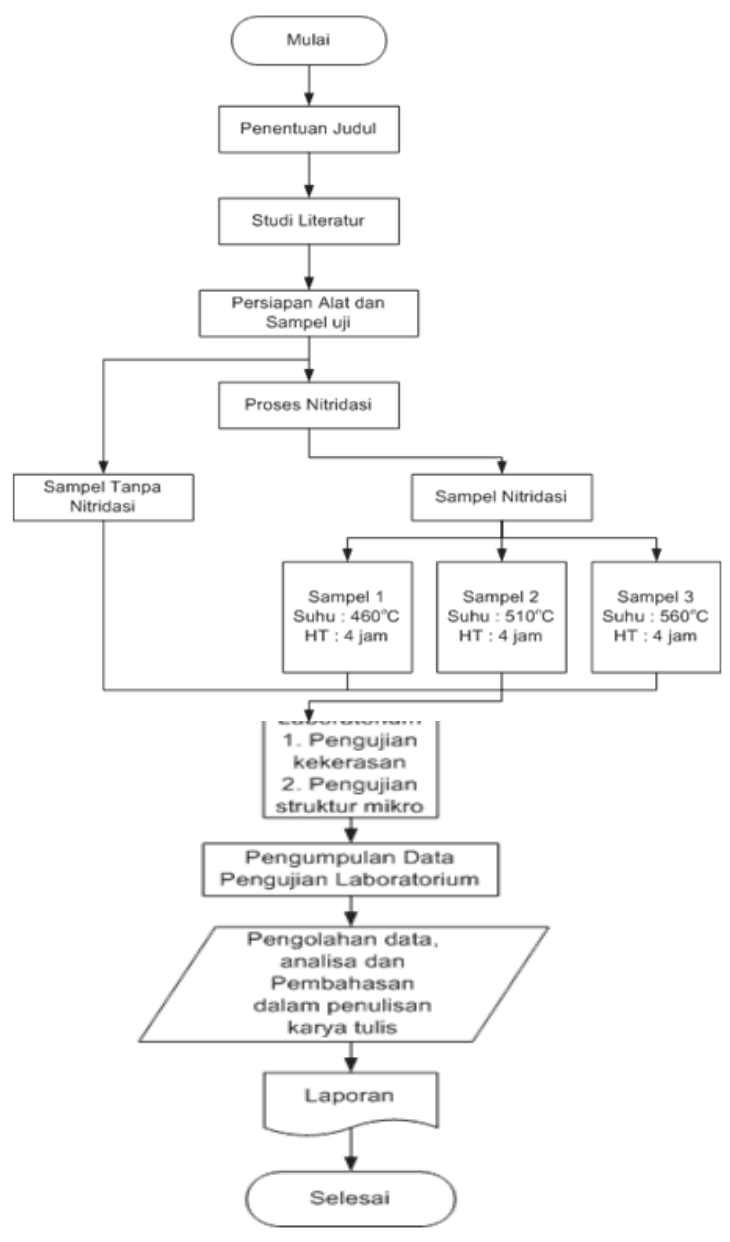

Gambar5. Diagram alir penelitian

\section{ANALISIS DAN PEMBAHASAN}

\section{Observasi Struktur Mikro}

Pengujian struktur mikro dilakukan bertujuan untuk mengetahui struktur mikro pada keempat sampel uji, baik pada sampel yang belum mengalami proses nitridasi, maupun yang sudah mengalami proses nitridasi dan mengetahui perubahan yang terjadi. Berikut adalah hasil dari observasi struktur mikro yang telah dilakukan:

\section{Sampel 0}

Merupakan sampel uji yang tidak mengalami proses nitridasi. Berikut adalah struktur mikro sampel 0 dengan perbesaran 500 kali:

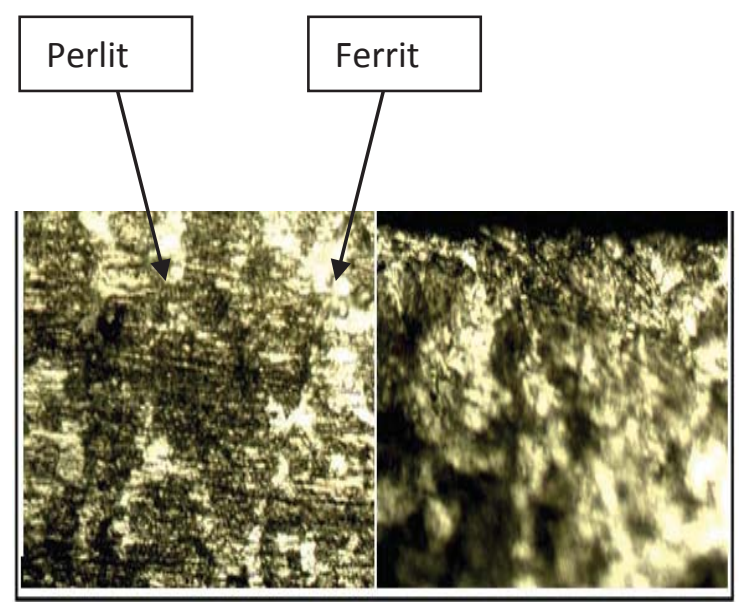

Gambar 6. Struktur mikro awal pembesaran 500x

\section{Sampel 1}

Merupakan sampel uji yang telah mengalami proses nitridasi dengan suhu pemanasan $460^{\circ} \mathrm{C}$ dan waktu penahanan 4 jam. Berikut adalah struktur mikro sampel 1 dengan perbesaran 500 kali:

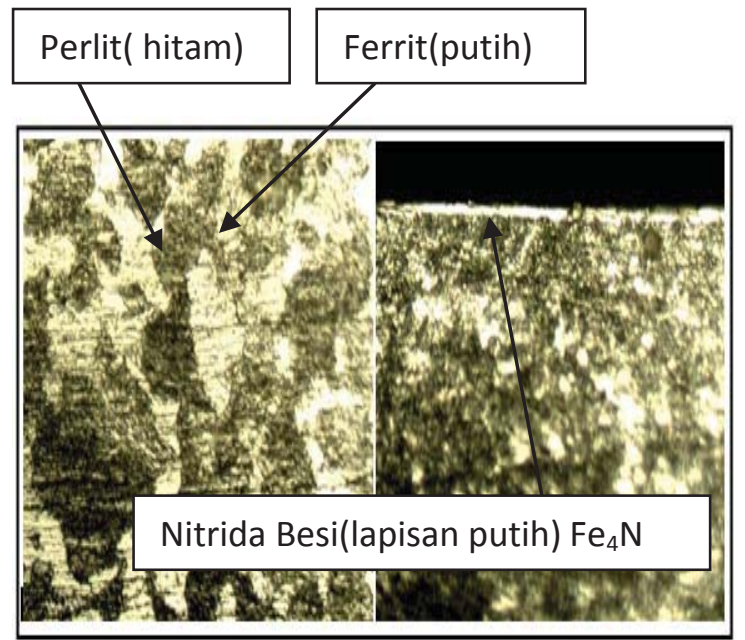

Gambar 7. Struktur mikro as Nitridasi $460^{\circ} \mathrm{C}$ pembesaran 500x

\section{Sampel 2}

Merupakan sampel uji yang telah mengalami proses nitridasi dengan suhu pemanasan $510^{\circ} \mathrm{C}$ dan waktu penahanan 4 jam. Berikut adalah struktur mikro sampel 2 dengan perbesaran 500 kali: 


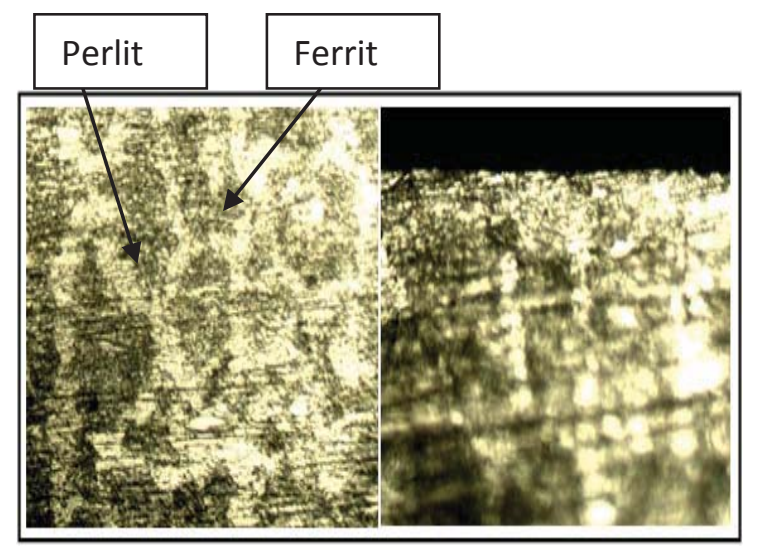

Gambar 8. Struktur mikro as nitridasi 510 ${ }^{\circ}$ Cpembesaran 500x

\section{Sampel 3}

Merupakan sampel uji yang telah mengalami proses nitridasi dengan suhu pemanasan $560^{\circ} \mathrm{C}$ dan waktu penahanan 4 jam. Berikut adalah struktur mikro sampel 3 dengan perbesaran 500 kali:

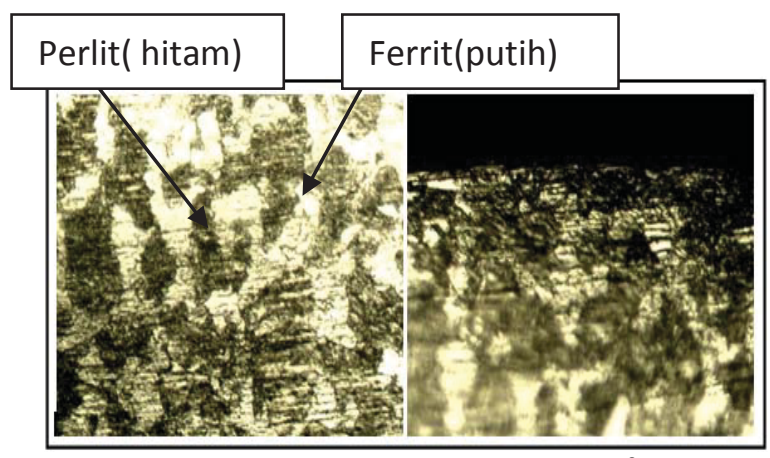

Gambar 9. Struktur mikro as nitridasi $560^{\circ} \mathrm{C}$

\section{Nitrida Besi Di Permukaan Baja}

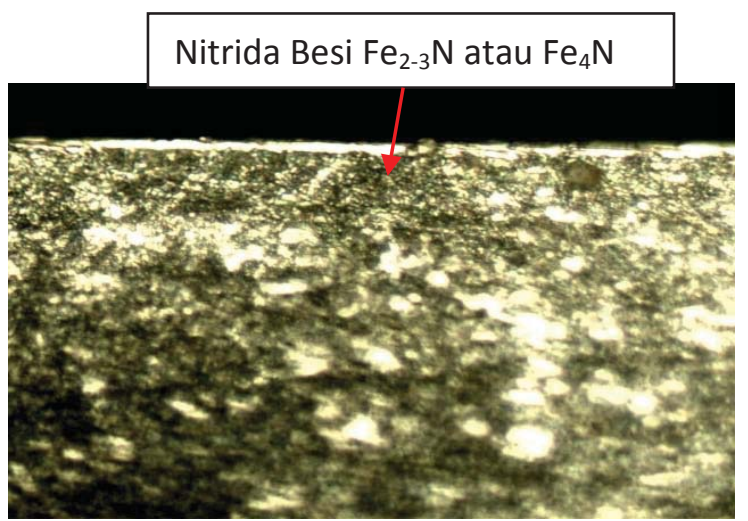

Gambar10. Lapisan putih White layer dipermukaan baja

Lapisan putih pada sisi terluar atau disebut white layer, yaitu nitrida yang terbentuk pada permukaan baja akibat dari difusi nitrogen terhadap permukaan baja membentuk lapisan nitrida $(\mathrm{FeN})$. Nitridasi ini dapat terjadi akibat atmosfer pada tungku pemanas yang banyak terdapat atom $(\mathrm{N})$ yang berasal dari $\mathrm{NH}_{2}$ yang terurai dari urea. Gas $\mathrm{NH}_{2}$ ini akan bereaksi melepaskan atom nitrogen (N) yang akan berdifusi dengan permukaan baja. Atom-atom nitrogen ini akan bereaksi dengan baja (Fe) untuk membentuk lapisan nitrida $\mathrm{Fe}_{2-3}{ }_{3} \mathrm{~N}$ atau $\mathrm{Fe}_{4} \mathrm{~N}$. Lapisan putih dipermukaan baja membentuk ikatan logam dan non logam sehingga terbentuk ikatan sejenis keramik yang membentuk material komposit yang keras,dan mempunyai sifat ketahanan aus yang tinggi.

\section{Pengujian Kekerasan Permukaan}

Pengujian ini bertujuan untuk mengetahui kekerasan permukaan sampel dan membandingkan hasil pengujian kekerasan yang telah dilakukan pada keempat sampel uji. Berikut adalah hasil pengujian mikro vickers dengan beban penetrasi 100 gram atau HV0.1. 


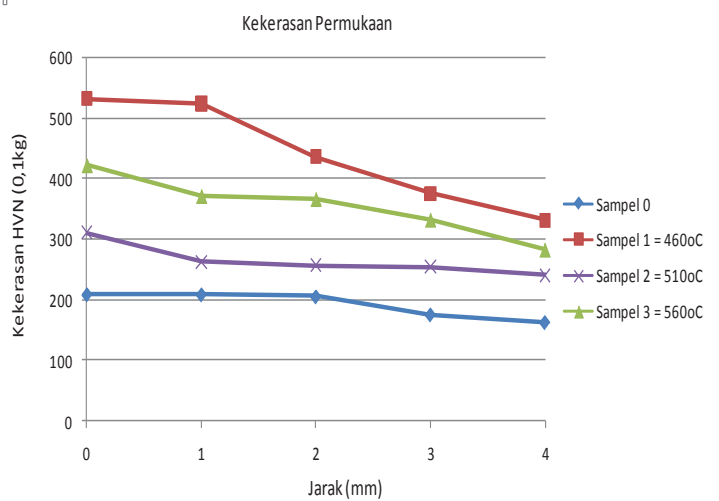

Gambar11. Hasil uji kekerasan permukaan pada ke 4 sampel

\section{Pengujian Depth of Case}

Pengujian ini dilakukan untuk mengetahui kedalaman difusi dari proses nitridasi pada ketiga sampel dan membandingkannya dengan sampel tanpa proses nitridasi. Pengujian dilakukan dengan memberikan jarak setiap pergeseran $0,05 \mathrm{~mm}$.

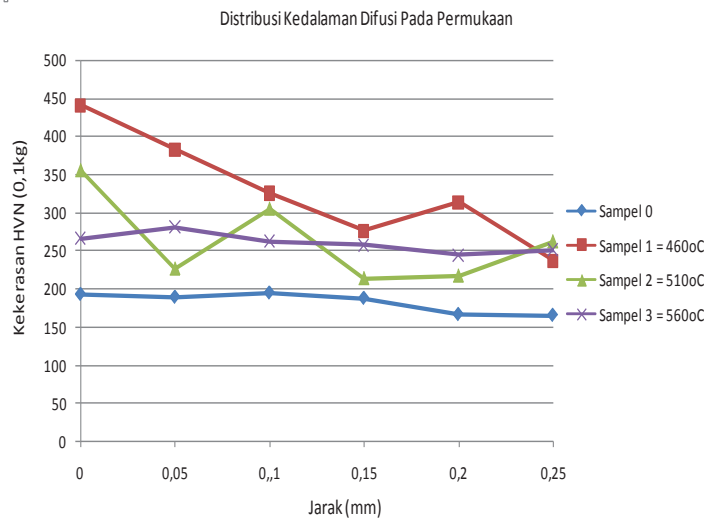

Gambar12. Hasil uji kedalaman kekerasan (DoC) dari ke 4 sampel uji

\section{KESIMPULAN}

Dari hasil uji nitridasi sebagai perlakuan permukaan baja dengan menggunakan urea sebagai sumber Nitrogen dapat disimpulkan sebagai berikut:
1. Proses nitridasi dengan menggunakan media urea sebanyak 250 gram sebagai sumber nitrogen dengan waktu penahanan di dalam tungku yang konstan dan variabel suhu yang berbeda-beda, maka didapatkan hasil kekerasan yang berbeda

2. Pengamatan struktur mikro pada penampang melintang dengan suhu $460{ }^{\circ} \mathrm{C}$ terlihat struktur inti tidak mengalami perubahan, yaitu sama dengan material awal sebelum dilakukan proses nitridasi namun terdapat lapisan putih pada permukaan, yaitu nitrida besi sedalan $\pm 25 \mu \mathrm{m}$.

3. Pengamatan kedalaman difusi nitrogen dengan kekerasan penampang melintang didapatkan peningkatan kekerasan dari material awal sampai kedalaman $25 \pm 25 \mu \mathrm{m}$ Dengan hasil ini pengerasan permukaan baja AISI 1045 dengan menggunakan media urea sebagai sumber nitrogen dapat meningkatkan kekerasan permukaan baja tersebut.

\section{Saran}

Untuk lebih sempurnanya penelitian, perlu adanya perbaikan dalam pembuatan tabung nitridasinya yaitu tabung nitridasi yang mudah dalam handlingnya.

\section{DAFTAR PUSTAKA}

[1] ASM Internasional, 1991, " Metals Handbook Heat Treating", Volume 4.

[2] Metallography, Structures, and Phase Diagrams, Vol 8, Metals Handbook, 8th ed., American Society for Metals, 1973.

[3] Mei Yang, "Nitriding - fundamentals, modeling and process optimization", Material Science and Engineering, Worcester Polytechnic Institute.

[4] Sunarto, "Pengaruh Surface Treatment Metoda Plasma Nitriding Terhadap Kekerasan dan Ketahanan Aus Pahat Bubut Bahan Baja Kecepatan Tinggi”, Jurnal Teknik Mesin Politeknik Negeri Semarang.

[5] Carbon Steel, Diakses tahun 2013. (On Line) Available at http//en.wikipedia.org (On Line).

[6] Chemical Composition of AISI 1045. Diakses tahun 2013. (On Line) Available at http//www.strindustries.com 